\title{
Adverse Peculiarity Arising with Overhead Power Lines
}

\author{
Josifs Survilo* \\ Riga Technical University
}

\begin{abstract}
In the paper, the power lines with flat arrangement of phases are considered. At the end of untransposed power lines, the unbalanced voltage appears. As an alternative to transposition, unbalanced load can be applied. Considerable difference of phase loads is the shortcoming of this method. A special increase of mutual inductance among outer phases would be a proper alternative if the way of its implementation would be found. Zero sequence is smaller for the line with overhead ground wires (OGW), especially when OGW is above the middle phase. Parallel lines have considerable mutual Fortesque impedances of all sequences, the most of them being zero sequence. The impact of parallel lines can be weakened by additive measures. Fault analysis of untransposed lines can be reduced to that of transposed.
\end{abstract}

Keywords - Parallel power lines, relay protection, transmission line, transposition, unbalanced voltage.

\section{INTRODUCTION}

Overhead power lines have a property comparatively few spoken about. They, considered in the 0-1-2 domain [1], besides impedances $Z_{0}, Z_{1}$, and $Z_{2}$ have mutual impedances $Z_{01}, Z_{02}, \ldots$. [2], which results in non-symmetrical voltages at the end of such lines.

Unbalanced voltages are highly unwanted for the loads, especially for electrical motors as well as for other loads [3], [4], [5].

Balanced lines (with phase conductors arranged in the vertices of equilateral triangle) theoretically have not mutual impedances $Z_{01}, Z_{02}, \ldots$, but they are uncomfortable in their construction.

Practical solution is such that, for balancing unbalanced lines, their transposition is used [6]; however, transposition is a costly measure [7]. It requires a special power-line support. Besides, as it is shown in [8], some types of relay protection can be implemented better without transposition.

In [8], it is shown that voltage at the end of an untransposed power line can be balanced by a non-symmetrical load. The practical possibility of this measure will be investigated further by appropriate calculations.

The issue has yet another side: 1) the overhead ground wires (OGW) are not conductive to balancing the power lines; 2 ) what is the situation with parallel lines, be they even balanced separately; this applies especially to double-circuit lines. It is considered that in parallel lines the only mutual Fortesque impedance is that of zero sequence. This should be investigated how it is in reality.

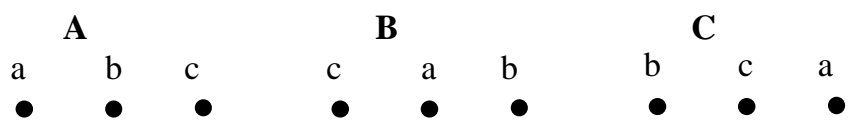

Fig. 1. Versions of phase a position.

The relay protection of such lines is another bunch of questions which are to be clarified.

\section{DETERMINATION OF UNBALANCED LOAD}

Obviously, the voltage at the end of an untransposed power line will be balanced when the voltages of phases $a b c$ are related in such a way:

$$
U_{\text {end.A }}=m U_{\text {end.B }}=m^{2} U_{\text {end.C }},
$$

where $m$ is vector operator [1], but $U_{\text {end }}$ (it is multiplied by $\left.\operatorname{det}\left(Z_{\mathrm{L} A B C \Sigma}\right)\right)$ according to [8] are:

$$
\begin{gathered}
\mathrm{U}_{\text {end.A }}=\left(\alpha_{\mathrm{A}}+a^{2} \beta+a \gamma\right) z_{\mathrm{A}} ; U_{\text {end.B }}=\left(\beta+a^{2} \alpha_{\mathrm{B}}+a \delta\right) z_{\mathrm{B}} ; \\
U_{\text {end. }}=\left(\gamma+a^{2} \delta+a \alpha_{\mathrm{C}}\right) z_{\mathrm{C}} .
\end{gathered}
$$

To make the calculation plausible, it is necessary to unscramble all the components of the expressions (2) referring to the sections 2 and 8 of [8], where $z_{\mathrm{d}}=0.148+0.7227 i$; $z_{\mathrm{s}}=0.05+0.3422 ; z_{\mathrm{f}}=0.05+0.2987 i$.

A. Phase a located to the left of phase conductor flat arrangement (Fig. 1a)

On the basis of [8] chapter 8 , we have:

$$
\begin{aligned}
& \alpha_{\mathrm{a}}=\left(z_{\mathrm{d}}+z_{\mathrm{b}}\right)\left(z_{\mathrm{d}}+z_{\mathrm{c}}\right)-z_{\mathrm{s}}^{2} ; \beta=z_{\mathrm{s}} z_{\mathrm{f}}-\left(z_{\mathrm{d}}+z_{\mathrm{c}}\right) z_{\mathrm{s}} ; \\
& \gamma=z_{\mathrm{s}}^{2}-\left(z_{\mathrm{d}}+z_{\mathrm{b}}\right) z_{\mathrm{f}} ; \alpha_{\mathrm{b}}=\left(z_{\mathrm{d}}+z_{\mathrm{a}}\right)\left(z_{\mathrm{d}}+z_{\mathrm{c}}\right)-z_{\mathrm{f}}{ }^{2} ; \\
& \delta=z_{\mathrm{s}} z_{\mathrm{f}}-\left(z_{\mathrm{d}}+z_{\mathrm{a}}\right) z_{\mathrm{s}} ; \alpha_{\mathrm{c}}=\left(z_{\mathrm{d}}+z_{\mathrm{a}}\right)\left(z_{\mathrm{d}}+z_{\mathrm{b}}\right)-z_{\mathrm{s}}{ }^{2} .
\end{aligned}
$$

In (2), load impedance $z_{\mathrm{A}}$ is set (after [8] it is equal to $0.98 \Omega$ ). Loads in the phases $b$ and $c$ are to be found. In batch (2), two equations (bearing in mind (1)) are independent since,

* Corresponding author.

E-mail address: survilo@eef.rtu.lv 
the load impedance $z_{\mathrm{A}}$ given, impedances $z_{\mathrm{B}}$ and $z_{\mathrm{C}}$ can be found.

Inserting equations (3) in expressions (2) and observing (1), we have:

$$
\begin{gathered}
U_{\text {end.A }}=z_{\mathrm{A}} z_{\mathrm{B}} z_{\mathrm{C}}+A_{\mathrm{B}} z_{\mathrm{B}}+A_{\mathrm{C}} z_{\mathrm{C}}+A_{0} ; \\
a U_{\text {end.B }}=z_{\mathrm{A}} z_{\mathrm{B}} z_{\mathrm{C}}+B_{\mathrm{B}} z_{\mathrm{B}}+B_{\mathrm{BC}} z_{\mathrm{B}} z_{\mathrm{C}} ; \\
a^{2} U_{\text {end.C }}=z_{\mathrm{A}} z_{\mathrm{B}} z_{\mathrm{C}}+C_{\mathrm{C}} z_{\mathrm{C}}+C_{\mathrm{BC}} z_{\mathrm{B}} z_{\mathrm{C}} ; \\
A_{\mathrm{B}}=\left(z_{\mathrm{d}}-a z_{\mathrm{f}}\right) z_{\mathrm{A}} ; A_{\mathrm{C}}=\left(z_{\mathrm{d}}-a^{2} z_{\mathrm{s}}\right) z_{\mathrm{A}} ; \\
A_{0}=\left[z_{\mathrm{d}}^{2}-z_{\mathrm{s}}^{2}+a^{2}\left(z_{\mathrm{f}}-z_{\mathrm{d}}\right) z_{\mathrm{s}}+a\left(z_{\mathrm{s}}^{2}-z_{\mathrm{d}} z_{\mathrm{f}}\right)\right] z_{\mathrm{A}} ; \\
B_{\mathrm{B}}=a\left(z_{\mathrm{f}}-z_{\mathrm{d}}\right) z_{\mathrm{s}}+\left(z_{\mathrm{d}}+z_{\mathrm{a}}\right) z_{\mathrm{d}}-\left(z_{\mathrm{f}}-a^{2} z_{\mathrm{s}}\right) z_{\mathrm{f}}- \\
-a^{2}\left(z_{\mathrm{d}}+z_{\mathrm{A}}\right) z_{\mathrm{s}} ; B_{\mathrm{BC}}=z_{\mathrm{d}}-a z_{\mathrm{s}} ; \\
C_{\mathrm{C}=} a^{2}\left(z_{\mathrm{s}}^{2}-z_{\mathrm{d}} z_{\mathrm{f}}\right)+a\left(z_{\mathrm{f}}-z_{\mathrm{d}}\right) z_{\mathrm{s}}+\left(z_{\mathrm{d}}+z_{\mathrm{A}}\right) z_{\mathrm{d}}- \\
-\left(z_{\mathrm{s}}+a z_{\mathrm{A}}\right) z_{\mathrm{s}} ; C_{\mathrm{BC}}=z_{\mathrm{d}}-a^{2} z_{\mathrm{f}} .
\end{gathered}
$$

Solving jointly $a U_{\text {end.B }}-U_{\text {end.A }}=0$ and $a^{2} U_{\text {end.C }}-U_{\text {end.A }}=0$, we obtain:

$$
\begin{aligned}
& D z_{\mathrm{B}}-E z_{\mathrm{C}}+F=0 ; \quad D=\left(B_{\mathrm{B}}-A_{\mathrm{B}}\right) C_{\mathrm{BC}}+A_{\mathrm{B}} B_{\mathrm{BC}} \\
& \left.E=A_{\mathrm{C}} C_{\mathrm{BC}}+C_{\mathrm{C}}-A_{\mathrm{C}}\right) B_{\mathrm{BC}} ; F=\left(B_{\mathrm{BC}}-C_{\mathrm{BC}}\right) A_{0} .
\end{aligned}
$$

Since

$$
z_{\mathrm{B}}=G z_{\mathrm{C}}-H ; G=E / D ; H=F / D
$$

Inserting $z_{\mathrm{B}}$ of (6) in $a^{2} U_{\text {end.C }}-U_{\text {end.A }}=0$, we obtain a quadratic equation:

$$
\begin{gathered}
a z_{\mathrm{C}}^{2}+b z_{\mathrm{C}}+c=0 ; a=C_{\mathrm{BC}} G ; b=C_{\mathrm{C}}-A_{\mathrm{C}}-A_{\mathrm{B}} G-C_{\mathrm{BC}} H ; \\
c=A_{\mathrm{B}} H-A_{0} .
\end{gathered}
$$

For imaginary part of $z_{\mathrm{C}}$ to be positive, the square root must be negative:

$$
z_{\mathrm{C}}=\frac{-b-\sqrt{b^{2}-4 a c}}{2 a} .
$$

Numerical results for the case in Fig. 1a are: $z_{\mathrm{A}}=0.98 ; z_{\mathrm{B}}=0.8836+0.0447 i ; z_{\mathrm{C}}=0.9360+0.1347 i$. Phase-to-phase loads have another character of distribution: $z_{\mathrm{AB}}=2.7766-0.0398 i ; z_{\mathrm{BC}}=2.6574+0.3437 i ;$ $z_{\mathrm{CA}}=2.9590+0.2314 i$.

Balancing the line with a set load in the phase $a$, which is located at the right side of the flat phase conductor displacement (Fig. 1c), we have the same results as in Fig. 1a.

\section{B. Phase a (with a set load) in the middle (Fig. 1b)}

Some expressions are different from those of batch (3):

$$
\begin{aligned}
& \alpha_{\mathrm{A}}=\left(z_{\mathrm{d}}+z_{\mathrm{B}}\right)\left(z_{\mathrm{d}}+z_{\mathrm{C}}\right)-z_{\mathrm{f}}^{2} ; \beta=z_{\mathrm{s}} z_{\mathrm{f}}-\left(z_{\mathrm{d}}+z_{\mathrm{C}}\right) z_{\mathrm{s}} ; \\
& \gamma=z_{\mathrm{s}} z_{\mathrm{f}}-\left(z_{\mathrm{d}}+z_{\mathrm{B}}\right) z_{\mathrm{s}} ; \alpha_{\mathrm{B}}=\left(z_{\mathrm{d}}+z_{\mathrm{A}}\right)\left(z_{\mathrm{d}}+\mathrm{z}_{\mathrm{C}}\right)-z_{\mathrm{s}}^{2} ; \\
& \quad \delta=z_{\mathrm{s}}^{2}-\left(z_{\mathrm{d}}+z_{\mathrm{A}}\right) z_{\mathrm{f}} ; \alpha_{\mathrm{C}}=\left(z_{\mathrm{d}}+z_{\mathrm{A}}\right)\left(z_{\mathrm{d}}+z_{\mathrm{B}}\right)-z_{\mathrm{s}}^{2} .
\end{aligned}
$$

The fillings of the coefficients $A_{\mathrm{B}}, \ldots, H$ are different.

Load impedances of the phases and phase-to-phase loads are the following:

$z_{\mathrm{A}}=0.98 ; z_{\mathrm{B}}=1.043+0.0966 i ; z_{\mathrm{C}}=1.0841-0.0549 i ;$

$z_{\mathrm{AB}}=2.9590+0.2313 i ; z_{\mathrm{BC}}=3.2863+0.0901 i ;$

$z_{\mathrm{CA}}=3.0693-0.1996 i$.

The acquired data show that this method requires a large amount of unbalanced load.

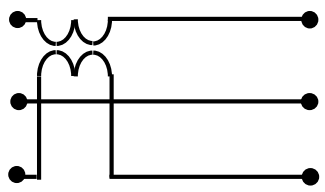

Fig. 2. Putative possibility of balancing the power line with flat arrangement of phases
In [8], it is shown that a power line becomes balanced if all mutual impedances are equal. If in flat arrangement of phases, the mutual inductance between two outside phases were equal to that between adjacent phases, then the power line would become balanced. This could be possible if such an ideal transformer
[9] existed with a predefined mutual impedance $M$ between two outer phases (Fig. 2). When a transformer is not ideal, on a par with mutual inductance the extra inductance in each of two phases appears. On the basis of [8], it can be said that an extra phase-to-phase capacitance would not play a significant role.

\section{POWER LINE WITH OVERHEAD GROUND WIRE}
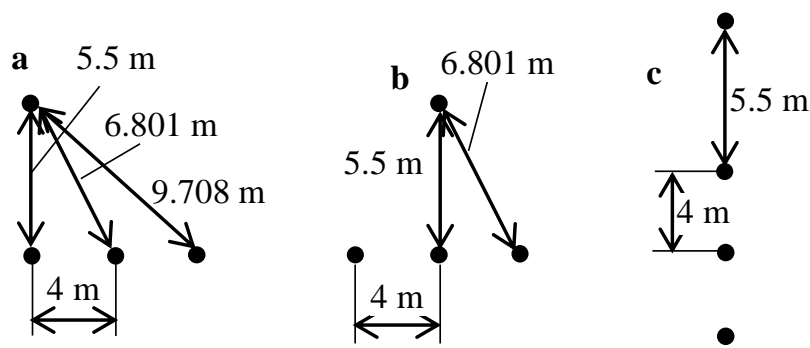

Fig. 3. Versions of OGW location and mutual distances.

This power line is considered with one OGW (Fig. 3), which consists of one conductor with the same parameters as phase conductor. The OGW with less conductivity should have less influence on line unbalance. Mutual reactances are calculated by (13) of [8]:

$$
x_{j k}=0.0627972 \lg \left(D_{z} / D_{j k}\right) \quad \Omega / \mathrm{km},
$$

where $D_{j k}$ is the distance between the conductors $j$ and $k$ (Fig. 3): $z_{\mathrm{d}}=0.148+0.7227 i ; z_{j k}=0.05+x_{j k}$.

For version a, mutual reactances between phase conductors are:

$$
x_{\mathrm{AB}}=x_{\mathrm{BA}}=0.3422 i
$$

$x_{\mathrm{AC}}=x_{\mathrm{CA}}=0.2987 i$;

$x_{\mathrm{BC}}=x_{\mathrm{CB}}=0.3422 i$.

Mutual reactances between phase conductor and OGW are: $x_{\mathrm{Ax}}=x_{\mathrm{xA}}=0.3222 i ; x_{\mathrm{Bx}}=\mathrm{x}_{\mathrm{xB}}=0.3088 i ; x_{\mathrm{Cx}}=\mathrm{x}_{\mathrm{xC}}=0.2865 i$.

In p. 9 of [1], it is shown that OGW causes a change in the components of $z_{\mathrm{ABC}}$ :

$$
z_{j j}^{\prime}=z_{\mathrm{d}}-\frac{z_{j \mathrm{x}} z_{\mathrm{x} j}}{z_{\mathrm{d}}} ; z_{j k}^{\prime}=z_{j k}-\frac{z_{j \mathrm{x}} z_{x k}}{z_{\mathrm{d}}} .
$$


For comparison, the impedance matrix without $\mathrm{OGW} Z_{\mathrm{ABC}}$, $Z_{012}$ and with OGW $Z^{\prime}{ }_{\mathrm{ABC} c}, Z^{\prime}{ }_{012}$ of versions a, b, c (Fig. 3) are shown.

Recall that $Z_{\mathrm{ABC}}$ and $Z_{012}$ impedance matrices of unbalanced lines look

$$
\text { as: } \quad Z_{\mathrm{ABC}}=\left[\begin{array}{ccc}
z_{\mathrm{aa}} & z_{\mathrm{ab}} & z_{\mathrm{ac}} \\
z_{\mathrm{ba}} & z_{\mathrm{bb}} & z_{\mathrm{bc}} \\
z_{\mathrm{ca}} & z_{\mathrm{cb}} & z_{\mathrm{cc}}
\end{array}\right] ; Z_{012}=\left[\begin{array}{ccc}
Z_{0} & Z_{01} & Z_{02} \\
Z_{10} & Z_{1} & Z_{12} \\
Z_{20} & Z_{21} & Z_{2}
\end{array}\right] \text {. }
$$

Their conversion is done by the expression (2.11) of [1], which for further references here is reproduced:

$$
Z_{012}=A Z_{\mathrm{ABC}} A^{-1}
$$

where $A-$ see [8].

The numerical results are shown below.

For flat (horizontal) arrangement of a power line without OGW:

$Z_{\mathrm{ABC}}=\left[\begin{array}{ccc}0.1480+0.7227 i & 0.0500+0.3422 i & 0.0500+0.2987 i \\ 0.0500+0.3422 i & 0.1480+0.7227 i & 0.0500+0.3422 i \\ 0.0500+0.2987 i & 0.0500+0.3422 i & 0.1480+0.7227 i\end{array}\right] ;$
$Z_{012}=\left[\begin{array}{ccc}0.2480+1.3781 i & 0.0126+0.0073 i & -0.0126-0.0072 i \\ -0.0126-0.0072 i & 0.0980+0.3950 i & -0.0251+0.0145 i \\ 0.0126-0.0072 i & 0.0251+0.0145 i & 0.0980+0.3950 i\end{array}\right]$.

Estimation of impedances:

$\left|Z_{1}\right|=\left|Z_{2}\right|=0.407 ; \quad\left|Z_{0}\right|=1.4002$, it is 3.4403 times of $\left|Z_{1}\right|$; $\left|Z_{01}\right|=\left|Z_{02}\right|=\left|Z_{10}\right|=\left|Z_{20}\right|=0.0146, \quad$ it is $3.58 \%$ of $\left|Z_{1}\right|$; $\left|Z_{12}\right|=\left|Z_{21}\right|=0.029$, it is $7.13 \%$ of $\left|Z_{1}\right|$.

For a power line with OGW:

version a:

$Z_{\mathrm{ABC}}^{\prime}=\left[\begin{array}{ccc}0.1328+0.5794 i & 0.0345+0.2048 i & 0.0340+0.1712 i \\ 0.0345+0.2048 i & 0.1322+0.5910 i & 0.0339+0.2199 i \\ 0.0340+0.1712 i & 0.0339+0.2199 i & 0.1316+0.6092 i\end{array}\right] ;$
$Z_{012}^{\prime}=\left[\begin{array}{ccc}0.2004+0.9905 i & 0.0049-0.0179 i & -0.0040-0.0172 i \\ -0.0040-0.0172 i & 0.0981+0.3946 i & -0.0247+0.0145 i \\ 0.0049-0.0179 i & 0.0247+0.0143 i & 0.0981+0.3946 i\end{array}\right]$

version b:

$Z_{\mathrm{ABC}}^{\prime}=\left[\begin{array}{ccc}0.1322+0.5910 i & 0.0345+0.2048 i & 0.0342+0.1670 i \\ 0.0345+0.2048 i & 0.1328+0.5794 i & 0.0345+0.2048 i \\ 0.0342+0.1670 i & 0.0345+0.2048 i & 0.1322+0.5910 i\end{array}\right] ;$
$Z_{012}^{\prime}=\left[\begin{array}{ccc}0.2012+0.9715 i & 0.0074-0.0046 i & -0.0077-0.0042 i \\ -0.0077-0.0042 i & 0.0980+0.3949 i & -0.0252+0.0145 i \\ 0.0074-0.0046 i & 0.0252+0.0146 i & 0.0980+0.3949 i\end{array}\right]$

version $\mathbf{c}$ :

$Z_{\mathrm{ABC}}^{\prime}=\left[\begin{array}{ccc}0.1328+0.5794 i & 0.0340+0.2140 i & 0.0336+0.1803 i \\ 0.0340+0.2140 i & 0.1316+0.6081 i & 0.0334+0.2364 i \\ 0.0336+0.1803 i & 0.0334+0.2364 i & 0.1312+0.6250 i\end{array}\right] ;$
$Z_{012}^{\prime}=\left[\begin{array}{ccc}0.1992+1.0246 i & 0.0055-0.0257 i & -0.0043-0.0252 i \\ -0.0043-0.0252 i & 0.0982+0.3939 i & -0.0242+0.0139 i \\ 0.0055-0.0257 i & 0.0245+0.0136 i & 0.0982+0.3939 i\end{array}\right]$.
We can see that zero Fortesque impedance of the line with OGW of all versions is less than that of the line without OGW, while positive and negative sequence impedances are equal to each other and on the same level as for a line without OGW. Mutual impedances for all cases obey such coherences: $Z_{12} \approx Z_{21}$ and approximately the same for all cases and equal $7 \%$ of $Z_{1} ; Z_{01}=Z_{20}$ and are greatest for the case $\mathbf{c}\left(6.5 \%\right.$ of $\left.Z_{1}\right)$.

To obtain evaluation of zero and negative sequence currents, we proceed in such a way as it was done in [8].

The percentage of three-phase short circuit zero sequence $I_{0} \%$ and negative sequence $I_{2} \%$ currents with respect to direct sequence current for flat arrangement of phases were calculated in [8]; there also the unbalance indices $\mathrm{I}_{\mathrm{L} 0} \%$ and $\mathrm{I}_{\mathrm{L} 2} \%$ were calculated for the same line loaded with resistance in each phase $0.98 \Omega$ :

$I_{0} \%=1.11, I_{2} \%=7.16, I_{\mathrm{L} 0} \%=0.79, I_{\mathrm{L} 2} \%=2.54$.

These indices, calculated for the same line with OGW (Fig. 2) using the same procedure as in [8], are shown below.

Version a: $I_{0} \%=1.8, I_{2} \%=7.05, I_{\mathrm{L} 0} \%=1.17, I_{\mathrm{L} 2} \%=2.5$.

Version b: $I_{0} \%=0.94, I_{2} \%=7.17, I_{\mathrm{L} 0} \%=0.57$,

$I_{\mathrm{L} 2} \%=2.53$.

Version c: $I_{0} \%=2.46, I_{2} \%=6.93, I_{\mathrm{L} 0} \%=1.64, I_{\mathrm{L} 2} \%=2.46$.

It can be seen that the indices of zero sequence current of the line with OGW are worse for the versions $\mathbf{a}$ and $\mathbf{c}$. The negative sequence current keeps approximately the same level.

\section{PARALLEL POWER LINES}

For well-transposed [1], in other words - totally transposed [2], two parallel lines, the positive and negative sequence mutual impedances do not exist (they are zero), while it should be reckoned with zero sequence impedance. Well-transposed two parallel lines have 12 transpositions [2]: nine transpositions for the first line, and three for the second one. Since transposition is an expensive undertaking, it is worth to study how things are without transposition. A double-circuit line consists of two lines located near each other since they are hung on the same support. The impact of mutual impedances should be considered.

Voltage drop in each phase of such a line consists of 6 terms from its own current, currents of two remaining phases, and currents of three phases of the adjacent line:

$$
\Delta U_{\mathrm{ABC}}=Z_{\mathrm{ABC}} I_{\mathrm{ABC}},
$$

where

$$
Z_{\mathrm{ABC}}=\left[\begin{array}{cccccc}
z_{\mathrm{aa}} & z_{\mathrm{ab}} & z_{\mathrm{ac}} & z_{\mathrm{aa}} & z_{\mathrm{ab}^{\prime}} & z_{\mathrm{ac}^{\prime}} \\
z_{\mathrm{ba}} & z_{\mathrm{bb}} & z_{\mathrm{bc}} & z_{\mathrm{ba}^{\prime}} & z_{\mathrm{bb}^{\prime}} & z_{\mathrm{bc}^{\prime}} \\
z_{\mathrm{ca}} & z_{\mathrm{cb}} & z_{\mathrm{cc}} & z_{\mathrm{ca}^{\prime}} & z_{\mathrm{cb}^{\prime}} & z_{\mathrm{cc}^{\prime}} \\
z_{\mathrm{a}^{\prime} \mathrm{a}} & z_{\mathrm{a}^{\prime} \mathrm{b}} & z_{\mathrm{a}^{\prime c}} & z_{\mathrm{a}^{\prime} \mathrm{a}^{\prime}} & z_{\mathrm{a}^{\prime} \mathrm{b}^{\prime}} & z_{\mathrm{a}^{\mathrm{c}^{\prime}}} \\
z_{\mathrm{b}^{\prime} \mathrm{a}} & z_{\mathrm{b}^{\prime} \mathrm{b}} & z_{\mathrm{b}^{\prime} \mathrm{c}} & z_{\mathrm{b}^{\prime} \mathrm{a}^{\prime}} & z_{\mathrm{b}^{\prime} \mathrm{b}^{\prime}} & z_{\mathrm{b}^{\prime} \mathrm{c}^{\prime}} \\
z_{\mathrm{c}^{\prime} \mathrm{a}} & z_{\mathrm{c}^{\prime} \mathrm{b}} & z_{\mathrm{c}^{\prime} \mathrm{c}} & z_{\mathrm{c}^{\prime} \mathrm{a}^{\prime}} & z_{\mathrm{c}^{\prime} \mathrm{b}^{\prime}} & z_{\mathrm{c}^{\prime} \mathrm{c}^{\prime}}
\end{array}\right] ; \mathrm{I}_{\mathrm{ABC}}=\left[\begin{array}{c}
I_{\mathrm{a}} \\
I_{\mathrm{b}} \\
I_{\mathrm{c}} \\
I_{\mathrm{a}^{\prime}} \\
I_{\mathrm{b}^{\prime}} \\
I_{\mathrm{c}^{\prime}}
\end{array}\right]
$$


Further it will be shown that two balanced but not transposed lines have mutual Fortesque impedances not only for zero sequences. For this reason, the arrangement of a double-circuit line is shown in Fig. 4. The phases are located in the vertices of equilateral triangles.

Based on the sections 2 and 3, we have: $z_{\mathrm{d}}=0.148+0.7227 i$

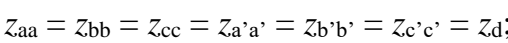

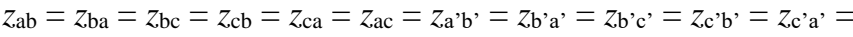
$z_{\mathrm{a}^{\prime} \mathrm{c}^{\prime}}=0.05+0.3422 i$

$z_{\mathrm{aa}^{\prime}}=z_{\mathrm{a}^{\prime} \mathrm{a}}=z_{\mathrm{bb}^{\prime}}=\mathrm{z}_{\mathrm{b}^{\prime} \mathrm{b}}=z_{\mathrm{cc}}{ }^{\prime}=z_{\mathrm{c}^{\prime}{ }^{\prime} \mathrm{c}}=0.05+0.2986 i$;

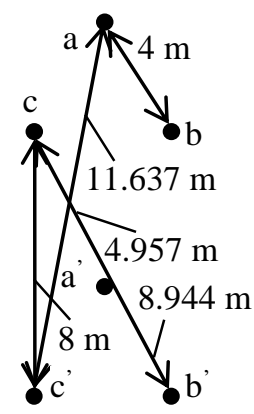

Fig. 4. Balanced power lines and Fig. 5. Power line on tower PB26. mutual distances.

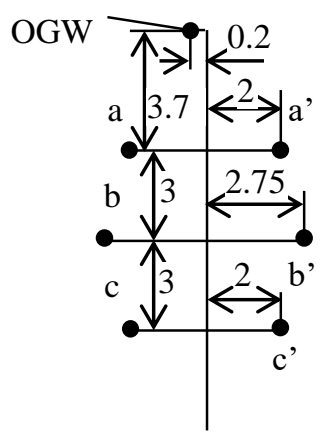

Distances are given in meters. $z_{\mathrm{ab}}{ }^{\prime}=z_{\mathrm{b}^{\prime} \mathrm{a}}=z_{\mathrm{ac}}=z_{\mathrm{c}^{\prime} \mathrm{a}}=0.05+0.2751 i$

$z_{\mathrm{bc}}{ }^{\prime}=z_{\mathrm{c}^{\prime} \mathrm{b}}=z_{\mathrm{cb}}{ }^{\prime}=z_{\mathrm{b}^{\prime} \mathrm{c}}=0.05+0.2916 i$

$z_{\mathrm{ba}}{ }^{\prime}=z_{\mathrm{a}}{ }^{\prime} \mathrm{b}=z_{\mathrm{ca}}{ }^{\prime}=z_{\mathrm{ac}}{ }^{\prime}=0.05+0.3287 i$.

The matrix $Z_{\mathrm{abc}}$ (see (15)) consists of four quarters with

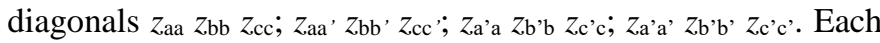
of these quarters is converted to a quarter in 012 domain according to (13). Hence, we can write:

$$
Z_{012}=\left[\begin{array}{cc}
A & 0 \\
0 & A
\end{array}\right] Z_{\mathrm{abc}}\left[\begin{array}{cc}
A^{-1} & 0 \\
0 & A^{-1}
\end{array}\right]
$$

This question is raised in [2], but a clear formula there is not given.

Equations (14) and (15) in Fortesque notation are:

$$
\Delta U_{012}=Z_{012} I_{012}
$$

where according to (16) we have $\boldsymbol{Z}_{\mathbf{0 1 2}}$ and $\boldsymbol{I}_{\mathbf{0 1 2}}$ converted from $\boldsymbol{Z}_{\text {abc }}$ and $\boldsymbol{I}_{\text {abc }}$ in a usual way $\left((13)\right.$ and $\left.\boldsymbol{I}_{\mathbf{0 1 2}}=\boldsymbol{A} \boldsymbol{I}_{\text {abc }}\right)$ :

$$
Z_{012}=\left[\begin{array}{cccccc}
z_{0} & z_{01} & z_{02} & z_{00^{\prime}} & z_{01^{\prime}} & z_{02^{\prime}} \\
z_{10} & z_{1} & z_{12} & z_{10^{\prime}} & z_{11^{\prime}} & z_{12^{\prime}} \\
z_{20} & z_{21} & z_{2} & z_{20^{\prime}} & z_{21^{\prime}} & z_{22^{\prime}} \\
z_{0^{\prime} 0} & z_{0^{\prime} 1} & z_{0^{\prime} 2} & z_{0^{\prime}} & z_{1^{\prime} 0^{\prime}} & z_{0^{\prime} 2^{\prime}} \\
z_{1^{\prime} 0} & z_{1^{\prime} 1} & z_{1^{\prime} 2} & z_{1^{\prime} 0^{\prime}} & z_{1^{\prime}} & z_{1^{\prime} 2^{\prime}} \\
z_{2^{\prime} 0} & z_{2^{\prime} 1} & z_{2^{\prime} 2} & z_{2^{\prime} 0^{\prime}} & z_{2^{\prime} 1^{\prime}} & z_{2^{\prime}}
\end{array}\right] ; I_{012}=\left[\begin{array}{c}
I_{0} \\
I_{1} \\
I_{2} \\
I_{0^{\prime}} \\
I_{1^{\prime}} \\
I_{2^{\prime}}
\end{array}\right] .
$$

The numerical results are shown in the Tables I and II.

\begin{tabular}{|c|c|}
\hline $\begin{array}{l}\text { First } \\
\text { symbol }\end{array}$ & Second symbol $\rightarrow \quad 0$ \\
\hline 0 & $0.15+0.8955 i ; 0.0302 i ; 0.0302 i$ \\
\hline 1 & $-0.0234 i ; 0.0001 i ;-0.0069 i$ \\
\hline 2 & $0 ; 0 ; 0.098+0.3805 i ; \quad-0.0234 i ;-0.0069 i ; 0.0001 i$ \\
\hline $0^{\prime}$ & 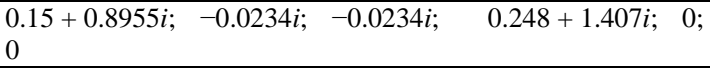 \\
\hline 1' & $\begin{array}{l}0.0302 i ; \quad 0.0001 i ; \quad-0.0069 i \\
0\end{array}$ \\
\hline $2^{\prime}$ & $0.0302 i ;-0.0069 i ; 0.0001 i$ \\
\hline
\end{tabular}

TABLE I

DATA OF $Z_{012}$ FOR BALANCED PARALLEL LINES

\begin{tabular}{|c|c|}
\hline \multirow{2}{*}{$\begin{array}{l}\text { First } \\
\text { symbol }\end{array}$} & $Z_{j j}$ are given in $\Omega$, the rest $\left(Z_{01} ; Z_{00}, \ldots\right)-$ in $\%$ of $Z_{11}$ \\
\hline & Second symbol $\rightarrow \quad 0 ; \quad 1 ; \quad 2 ; \quad 0 ; \quad 1 ;$ \\
\hline 0 & $Z_{00}=1.4288=3.6365 Z_{11} ; 0 ; 0 ;$ \\
\hline 1 & $0 ; \quad Z_{11}=0.3929 ; 0$ \\
\hline 2 & $0 ; 0 ; Z_{22}=0.3929=Z_{11}$ \\
\hline 0 , & $Z_{0^{\prime} 0^{\prime}}=1.4287=0.9993 Z_{00} ; 0 ; 0$ \\
\hline 1 , & $0 ; Z_{1}{ }^{\prime},=0.3929=Z_{11} ; 0$ \\
\hline 2 , & $0 ; 0 ; Z_{2}{ }^{\prime}{ }^{\prime}=0.3929=Z_{1}{ }^{\prime}$ \\
\hline
\end{tabular}

TABLE II

COMPARATIVE DATA OF $Z_{012}$ ABSOLUTE VALUES

The main impedances are:

a) $0.248+1.4071 i$, absolute value $(\rightarrow) 1.4288$ - zero sequence (z.s.) of each line separately, 3.6365 times of positive sequence (p.s.);

b) $0.098+0.3805 i \rightarrow 0.3929-$ p.s. and negative sequence (n.s.) of each line separately;

c) 0 - all mutual of each (balanced) line separately;

d) $0.15+0.8955 i \rightarrow 0.908-$ acknowledged mutual z.s. $\rightarrow 231.10 \%$ of p.s.; $63.55 \%$ of z.s. of each line separately.

Impedances a), b), and c) are such as each of two lines be a single one. There is no option of phase location of two parallel lines in such a way that all mutual distances between all phases would be equal. Be it so, without any transposition, the only mutual impedance would be that of zero sequence.

We can conclude that a parallel line has a tangible impact through its zero sequence current not only on zero sequence but on the positive and negative sequence of the adjacent line as well even when both lines are balanced.

\section{Double CiRCuit Line ON TOWER PB26}

Another location of wires using the tower PB26 will be considered (Fig. 5).

Firstly, we calculate the double-circuit line without OGW. Output data are given in the Tables III and IV. 
TABLE III

DATA OF $Z_{012}$ FOR PARALLEL LINES WITHOUT OGW USING TOWER PB 26

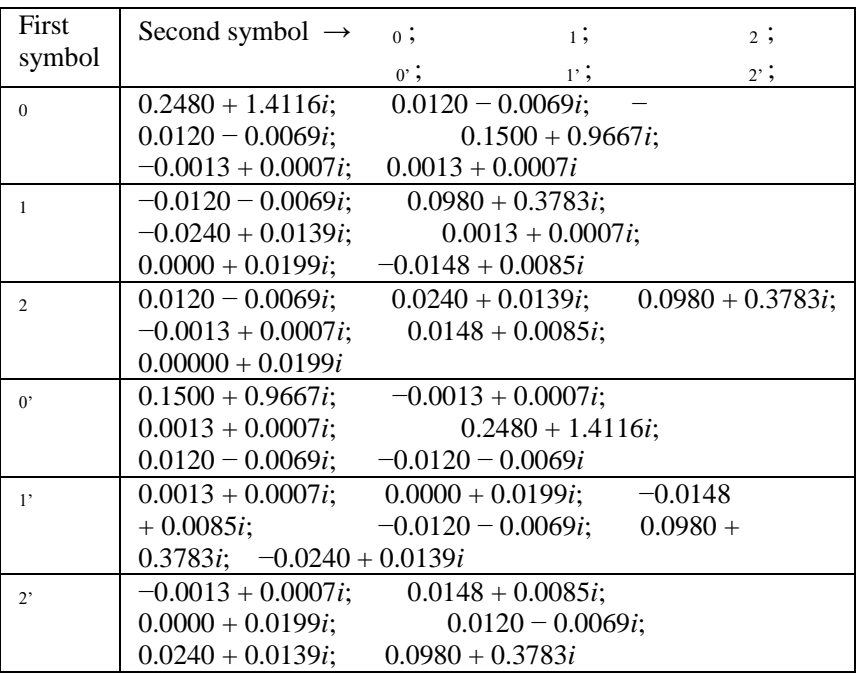

TABLE IV

COMPARATIVE DATA OF $Z_{012}$ ABSOLUTE VALUE FOR LINES WITHOUT OGW

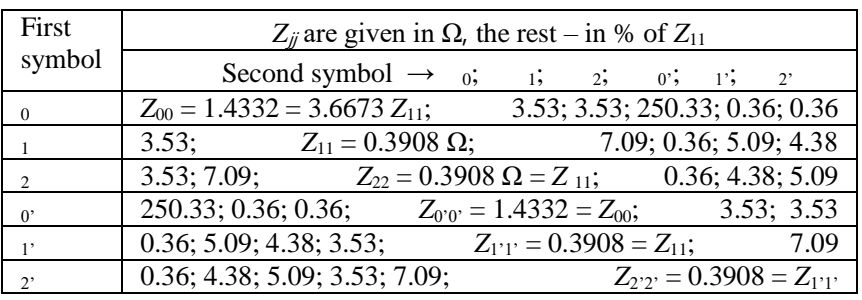

Unlike balanced parallel lines, mutual Fortesque impedances in each line separately are not equal to zero.

OGW brings in substantial changes as it is seen in the Tables $\mathrm{V}$ and VI.

TABLE V

DATA OF $Z_{012}$ FOR PARALLEL LINES WITH OGW USING TOWER PB 26

\begin{tabular}{|c|c|c|c|}
\hline $\begin{array}{l}\text { First } \\
\text { symb }\end{array}$ & Second symbol $\rightarrow$ & $\begin{array}{l}0 \\
0\end{array}$ & $\begin{array}{l}2 \\
2\end{array}$ \\
\hline 0 & $\begin{array}{l}0.2009+1.0125 i \\
0.1029+0.5693 i\end{array}$ & $\begin{array}{l}0.0520-0.0265 i \\
\quad-0.0076-0.0179 i\end{array}$ & $\begin{array}{c}-0.0036-0.0260 i \\
0.0092-0.0173 i\end{array}$ \\
\hline 1 & $\begin{array}{l}-0.0038-0.0255 i \\
-0.0078-0.0186 i\end{array}$ & $\begin{array}{r}0.0979+0.3771 i \\
0.0143+0.0077 i\end{array}$ & $\begin{array}{c}-0.0229+0.0131 i \\
0.0002+0.0189 i\end{array}$ \\
\hline 2 & $\begin{array}{l}0.0054-0.0260 i \\
-0.0078-0.0186 i\end{array}$ & $\begin{array}{l}0.0232+0.0129 i \\
\quad 0.0143+0.0073 i\end{array}$ & $\begin{array}{c}0.0985+0.3771 i \\
0.0002+0.0189 i\end{array}$ \\
\hline $0^{\prime}$ & $\begin{array}{l}0.1029+0.5693 i \\
0.2007+1.0328 i\end{array}$ & $\begin{array}{l}-0.0078-0.0186 i \\
-0.0087-0.0338 i\end{array}$ & $\begin{array}{c}0.0094-0.0180 i \\
0.0102-0.0332 i\end{array}$ \\
\hline $1^{\prime}$ & $\begin{array}{l}0.0092-0.0173 i \\
0.0102-0.0332 i\end{array}$ & $\begin{array}{c}0.0002+0.0189 i \\
0.0982+0.3940 i\end{array}$ & $\begin{array}{c}-0.0140+0.0080 i \\
-0.0376+0.0050 i\end{array}$ \\
\hline $2^{\prime}$ & $\begin{array}{l}-0.0076-0.0179 i \\
-0.0087-0.0338 i\end{array}$ & $\begin{array}{c}0.0143+0.0077 i \\
0.0380+0.0047 i\end{array}$ & $\begin{array}{c}0.0002+0.0179 i \\
0.0982+0.3940 i\end{array}$ \\
\hline
\end{tabular}

TABLE VI

COMPARATIVE DATA OF $Z_{012}$ ABSOLUTE VALUE FOR LINE WITH OGW

\begin{tabular}{|c|c|}
\hline \multirow{2}{*}{$\begin{array}{l}\text { First } \\
\text { symbol }\end{array}$} & $Z_{i j}$ are given in $\Omega$, the rest - in $\%$ of $Z_{11}$ \\
\hline & Second symbol $\rightarrow \quad 0 ; \quad{ }_{1} ; \quad 2 ; \quad 0 ; \quad 1 ;$ \\
\hline 0 & $14.99 ; 6.72 ; 148.49 ; 4.98 ; 5.03$ \\
\hline 1 & $6.62 ; \quad Z_{11}=0.3896 \Omega ; \quad 6.78 ; 5.18 ; 4.16 ; 4.85$ \\
\hline 2 & $6.83 ; 6.80 ; \quad Z_{22}=0.3898 \Omega=1.0005 Z_{11} ; \quad 5.18 ; 4.11 ; 4.85$ \\
\hline 0 , & $148.61 ; 5.18 ; 5.21 ; \quad Z_{0^{\prime} 0^{\prime}}=1.0521=1.0193 Z_{00} ; \quad 8.96 ; 8.91$ \\
\hline 1 , & $5.03 ; 4.85 ; 4.13 ; 8.91 ; \quad Z_{1}{ }^{\prime},=0.4060=1.0421 Z_{11} ; \quad 9.73$ \\
\hline 2 & $4.98 ; 4.16 ; 4.59 ; 8.96 ; 9.83 ; \quad Z_{2}{ }^{\prime}{ }^{\prime}=0.4061=1.00025 Z_{1^{\prime}{ }^{\prime}}$ \\
\hline
\end{tabular}

In parallel lines with OGW, the positive and negative sequence impedances slightly differ within one line, and to a greater degree - between two lines.

Some mutual impedances of a line with OGW strongly differ from those of a line without OGW.

\section{IMPACT ON RELAY PROTECTION}

In further exposition, complex quantities are not specifically marked as having difficulty in writing and understanding.

In the lines, we see two types of irregularities: the first, mutual Fortesque impedances of a single line do not equal zero; the second, mutual impedances between parallel lines appear. If these effects are strong enough, they must be neutralized in the relay protection, but the ways to achieve this are different for both types of irregularities.

The numerical technique gives excellent possibility to cope with the irregularity of the second type, i.e., with the influence of a parallel line. This statement can be done by observing the expressions (14) and (15).

To leave behind in the expression (15) only quantities without dashes, it is necessary to subtract from $\boldsymbol{U}_{\text {abcm }}$ (Fig. 6a)
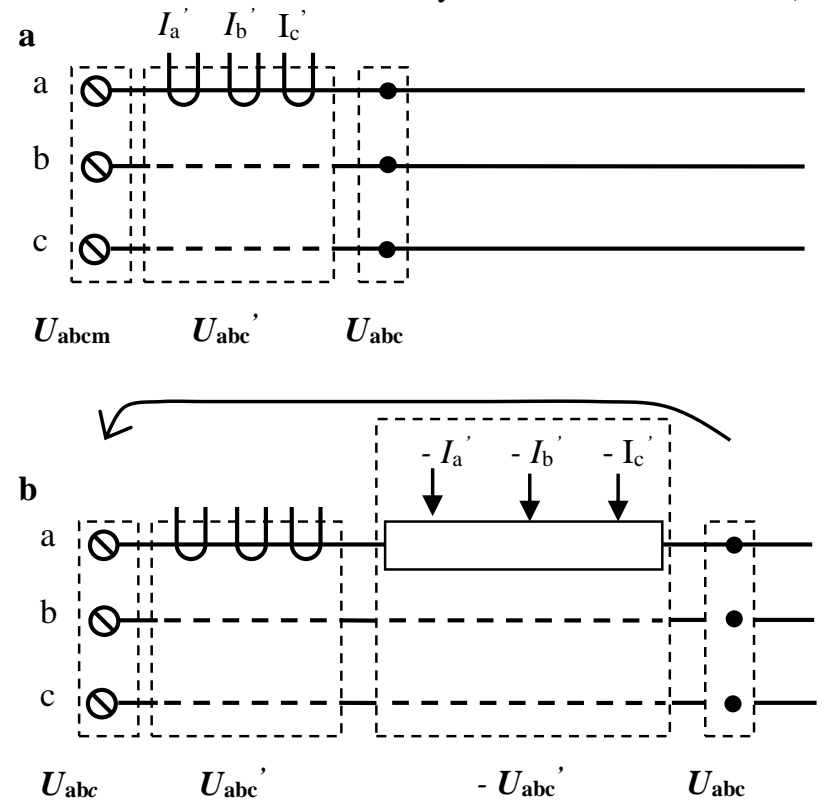

Fig. 6. Elimination of parallel line influence.

defined by (19)

$$
U_{\mathrm{abcm}}=\left[\begin{array}{cccccc}
z_{\mathrm{aa}} I_{\mathrm{a}} & z_{\mathrm{ab}} I_{\mathrm{b}} & z_{\mathrm{ac}} I_{\mathrm{c}} & z_{\mathrm{aa}^{\prime}} I_{\mathrm{a}^{\prime}} & z_{\mathrm{ab}^{\prime}} I_{\mathrm{b}^{\prime}} & z_{\mathrm{ac}^{\prime}} I_{\mathrm{c}^{\prime}} \\
z_{\mathrm{ba}} I_{\mathrm{a}} & z_{\mathrm{bb}} I_{\mathrm{b}} & z_{\mathrm{bc}} I_{\mathrm{c}} & z_{\mathrm{ba}^{\prime}} I_{\mathrm{a}^{\prime}} & z_{\mathrm{bb}^{\prime}} I_{\mathrm{b}^{\prime}} & z_{\mathrm{bc}^{\prime}} I_{\mathrm{c}^{\prime}} \\
z_{\mathrm{ca}} I_{\mathrm{a}} & z_{\mathrm{cb}} I_{\mathrm{b}} & z_{\mathrm{cc}} I_{\mathrm{c}} & z_{\mathrm{ca}^{\prime}} I_{\mathrm{a}^{\prime}} & z_{\mathrm{cb}^{\prime}} I_{\mathrm{b}^{\prime}} & z_{\mathrm{cc}^{\prime}} I_{\mathrm{c}^{\prime}}
\end{array}\right] ;(1,
$$

dashed summand $U_{\text {abc' }}$ (Fig. 5b) defined by (20)

$$
U_{\mathrm{abc}}{ }^{\prime}=\left[\begin{array}{ccc}
z_{\mathrm{aa}^{\prime}} I_{\mathrm{a}^{\prime}} & z_{\mathrm{ab}^{\prime}} I_{\mathrm{b}^{\prime}} & z_{\mathrm{ac}^{\prime}} I_{\mathrm{c}^{\prime}} \\
z_{\mathrm{ba}^{\prime}} I_{\mathrm{a}^{\prime}} & Z_{\mathrm{bb}^{\prime}} I_{\mathrm{b}^{\prime}} & z_{\mathrm{bc}^{\prime}} I_{\mathrm{c}^{\prime}} \\
z_{\mathrm{ca}^{\prime}} I_{\mathrm{a}^{\prime}} & z_{\mathrm{cb}^{\prime}} I_{\mathrm{b}^{\prime}} & z_{\mathrm{cc}^{\prime}} I_{\mathrm{c}^{\prime}}
\end{array}\right]
$$

and we shall have the remainder $U_{\text {abc }}$ (Fig. 6b) defined by (21) 


$$
U_{\mathrm{abc}}=\left[\begin{array}{ccc}
\mathrm{z}_{\mathrm{aa}} I_{\mathrm{a}} & z_{\mathrm{ab}} I_{\mathrm{b}} & z_{\mathrm{ac}} I_{\mathrm{c}} \\
z_{\mathrm{ba}} I_{\mathrm{a}} & Z_{\mathrm{bb}} I_{\mathrm{b}} & z_{\mathrm{bc}} I_{\mathrm{c}} \\
z_{\mathrm{ca}} I_{\mathrm{a}} & z_{\mathrm{cb}} I_{\mathrm{b}} & z_{\mathrm{cc}} I_{\mathrm{c}}
\end{array}\right],
$$

which is apt for a single untransposed line.

Now we have to cope with the irregularity of the first type, namely, with mutual impedances between the phases of the same line. This case for single-phase-to-earth, phase-to-phase, phase-to-phase-to-earth faults was considered in [8], whereat was shown that in relay protection technique, an untransposed line can be reduced to a transposed one taking into account how the conductor of a special phase is disposed.

The essence of this measure is that instead of Fortesque impedances $Z_{0}, Z_{1}, Z_{2}$, which moreover may not be equal (see Tables III-VI), the impedances $Z_{u 0}, Z_{u 1}, Z_{u 2}$ are employed. This gives an opportunity to exclude from consideration the mutual impedances between phases. Such impedances are different for specific types of short circuit, but expressions for short circuit calculation remain the same as for transposed lines.

Forasmuch as in some cases $Z_{u 1} \neq Z_{u 2}$, an approach to calculation of fault cases may be different from the conventional one. Such an approach is promoted by vast possibilities of the nowadays' computer technique. After the impact of parallel line removed, we can begin the formation of relay protection of an untransposed line. In [8], it is shown that with untransposed lines the principle of relay protection remains the same as if instead of the Fortesque impedances $Z_{012}$ the impedances for untransposed lines $Z_{u 012}$ are used. In further considerations, the subscript ${ }_{u}$ is omitted.

Recall the notation:

$$
Z_{0}=R_{0}+j X_{0} ; Z_{1}=R_{1}+j X_{1} ; Z_{2}=R_{2}+j X_{2} .
$$

For a considered line (or parallel lines), all components are known as linearly dependent on the positive sequence reactance:

$$
\begin{aligned}
& R_{0}=b_{0} X_{1} ; X_{0}=c_{0} X_{1} ; R_{1}=b_{1} X_{1} ; R_{2}=b_{2} X_{1} ; \\
& \quad X_{2}=c_{2} X_{1} .
\end{aligned}
$$

\section{A. Single Phase-to-earth Fault}

In one terminal line, the positive component of the shortcircuit current (as it derives from [10]) is:

$$
I_{1}=U /\left(Z_{0}+Z_{1}+Z_{2}\right)
$$

where $U$ is the faulty phase voltage at protection installation place; $I_{1}$ is the positive sequence current.

Here, the well-known theory will be presented in another way.

Protection operates when the first current component reaches its operation value $I_{1 o p}$ that takes place when the denominator of (24) assumes the value that is given by numerical impedance protection:

$$
Z_{\text {op }}=\frac{U}{I_{1}}=Z_{0}+Z_{1}+Z_{2}=R+j X
$$

Expression (24) can be overwritten as

$$
U=I_{1} Z_{\text {op }} .
$$

When fault occurs without fault resistance $R_{\mathrm{f}}$, the operating impedance is:

$$
\mathrm{Z}_{\mathrm{op}}=R_{0}+j X_{0}+R_{1}+j X_{1}+R_{2}+j X_{2} .
$$

Using (23) and denoting

$$
b=b_{0}+b_{1}+b_{2} ; c=c_{0}+1+c_{2},
$$

we can overwrite (26):

$$
Z_{\mathrm{op}}=X_{1}(b+j c) .
$$

Numerical protection gives operating impedance (25), and we have sought for the Fortesque impedance $X_{1}$ :

$$
X_{1}=\frac{R}{b} ; X_{1}=\frac{X}{c} .
$$

When a fault occurs through the fault resistance $R_{\mathrm{f}}$, we have

$$
U=I_{1} X_{1}(b+j c)+I_{1} R_{f}{ }^{*},
$$

where under $R_{\mathrm{f}}{ }^{*}$, tripled resistance to earth is understood.

Numerical protection gives apparent impedance $Z_{\text {opa }}$ :

$$
\begin{gathered}
Z_{\mathrm{opa}}=U / I_{1}=Z_{\mathrm{op}}+R_{\mathrm{f}}^{*}=R_{\mathrm{a}}+j X_{\mathrm{a}} ; \\
R_{\mathrm{a}}=X_{1} b+R_{\mathrm{f}}^{*} ; X_{\mathrm{a}}=X_{1} c .
\end{gathered}
$$

Out of (33) sought for positive sequence reactance to fault place and fault resistance readily can be found:

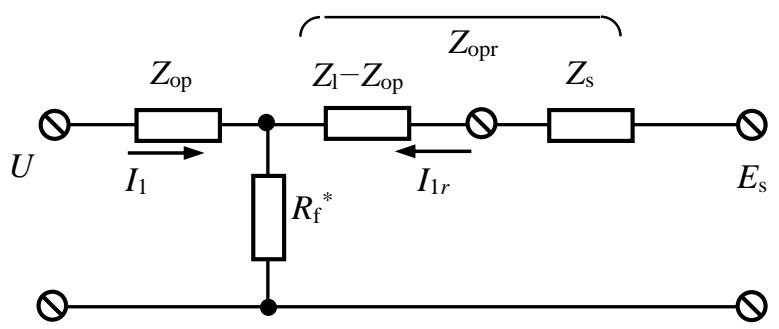

Fig. 7. Single phase-to-ground fault in a two-terminal power line.

$$
X_{1}=\frac{X_{\mathrm{a}}}{c} ; \quad R_{\mathrm{f}}^{*}=R_{\mathrm{a}}-\frac{b}{c} X_{\mathrm{a}}
$$

The situation is much more complicated for a two-terminal line (Fig. 7) where the fault is fed from two sides. Monitoring the line from one side it is not possible to give a definite answer how far from the monitoring point the fault occurs. More information from the opposite terminal of the line or some assumptions are needed. The latest proposal assumes that the network is homogenous [11]. But this cannot always be correct. 
Here a different approach is presented using the fact that the system impedance $Z_{\mathrm{s}}$ can be predefined. Observing Fig. 7, the expression (26) can be overwritten:

$$
U=I_{1} Z_{\text {op }}+\left(I_{1}+I_{1 \mathrm{r}}\right) R_{\mathrm{f}}{ }^{*}=I_{1} \mathrm{Z}_{\mathrm{op}}+I_{1}(1+\chi) R_{\mathrm{f}}{ }^{*},
$$

where $\chi$-vide infra.

Applying loop current method [12], we have (see Fig. 6):

$$
\begin{gathered}
I_{1}=\frac{U\left(Z_{\mathrm{opr}}+R_{\mathrm{f}}^{*}\right)-E_{\mathrm{s}} R_{\mathrm{f}}^{*}}{D} ; \\
I_{1 \mathrm{r}}=\frac{-U{R_{\mathrm{f}}}^{*}+E_{\mathrm{s}}\left(Z_{\mathrm{op}}+R_{\mathrm{f}}^{*}\right)}{D}
\end{gathered}
$$

and their ratio:

$$
\chi=\frac{I_{1 \mathrm{r}}}{I_{1}}=\frac{E_{\mathrm{s}} Z_{\mathrm{op}}+R_{\mathrm{f}}{ }^{*}\left(E_{s}-U\right)}{U Z_{\mathrm{opr}}-R_{\mathrm{f}}{ }^{*}\left(E_{\mathrm{s}}-U\right)} ; \chi^{\prime}=\operatorname{Re}(\chi) ; \chi^{\prime \prime}=\operatorname{Im}(\chi) .
$$

\section{Voltage $U$ is:}

$$
U=I_{1} Z_{\text {opa }}=I_{1}\left[X_{1} b+\left(1+\chi^{\prime}\right) R_{\mathrm{f}}^{*}+j\left(X_{1} c+\chi^{\prime \prime} R_{\mathrm{f}}^{*}\right)\right] .
$$

According to (32), relay protection calculates $R_{\mathrm{a}}$ and $X_{\mathrm{a}}$, which corresponding to (38) can be expressed as:

$$
R_{\mathrm{a}}=X_{1} b+\left(1+\chi^{\prime}\right) R_{\mathrm{f}}^{*} ; X_{\mathrm{a}}=X_{1} c+\chi^{\prime \prime} R_{\mathrm{f}}^{*},
$$

where from we have sought for quantities:

$$
X_{1}=\frac{\left(1+\chi^{\prime}\right) X_{\mathrm{a}}-\chi^{\prime \prime} R_{\mathrm{a}}}{c\left(1+\chi^{\prime}\right)-b \chi^{\prime \prime}} ; \quad R_{\mathrm{f}}^{*}=\frac{c R_{\mathrm{a}}-b X_{\mathrm{a}}}{c\left(1+\chi^{\prime}\right)-b \chi^{\prime \prime}} \text {. }
$$

It would be easy to find $X_{1}$ if the factor $\chi$ would be known. Unfortunately, it can be known when, according to (37), $Z_{\mathrm{op}}$ is known, which means - when $X_{1}$ is known. However, this does not mean that there is a vicious circle because really two expressions (36) must be satisfied and that can be done only with definite values of $R_{\mathrm{f}}{ }^{*}$ and $Z_{\mathrm{op}}$. But in two expressions (40), two more unknowns are present: $\chi$ ' and $\chi$ '”! Yet we should not forget the fact that $\chi$ in (37) is the function of unknowns $X_{1}$ and $R_{\mathrm{f}}{ }^{*}$. To break the vicious circle, in (40) for $\chi$ ' and $\chi$ ' ' must stand $f_{1}\left(X_{1}, R_{\mathrm{f}}{ }^{*}\right)$ and $f_{2}\left(X_{1}, R_{\mathrm{f}}{ }^{*}\right)$ respectively. Such modified expressions (40) are too complicated to solve them analytically. A simpler solution is to apply the iteration method.

For $Z_{\mathrm{a}}$ (its components are $R_{\mathrm{a}}$ and $X_{\mathrm{a}}$ ) given by relay protection, we assume some value of $X_{1 \text { as }}{ }^{(0)}$ and $R_{\text {fas }}^{*}{ }^{(0)}=0$. After (31), we calculate $\chi^{(1)}$. With this value inserted in (40), we calculate $X_{1}{ }^{(1)}$ and $R_{\mathrm{f}}{ }^{*(1)}$. Inserting these values as assumed in (31) and (40), we calculate $\chi^{(2)}, X_{1}^{(2)}, R_{\mathrm{f}}{ }^{*(2)}$, and so on, until the next value is close enough to the previous one.

In the expressions (36) and (37), a fresh quantity appears: emf $E_{\mathrm{s}}$ to the right of the line. This quantity is that very one which is assumed or calculated from the data of pre-fault mode.

\section{B. Phase-to-phase Fault}

The positive component of the short-circuit current is [10]:
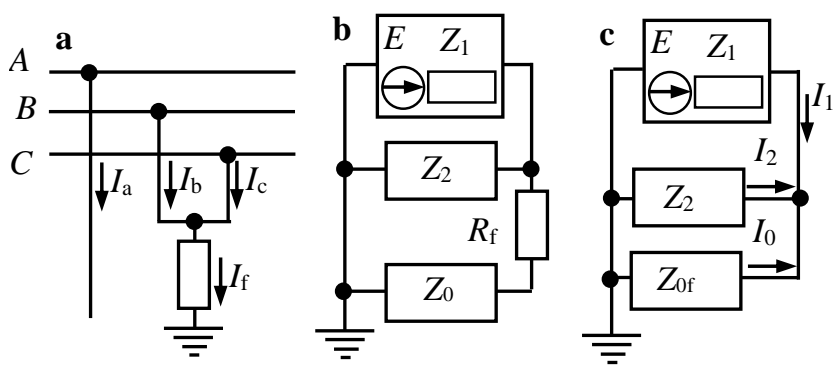

Fig. 8. Two-phase-to-ground fault: $\mathbf{a}$ - circuit diagram; $\mathbf{b}, \mathbf{c}$ - equivalent diagrams.

$$
I_{1}=\frac{U}{Z_{1}+Z_{2}}
$$

where $U$ is the voltage of the intact phase at protection installation place; $I_{1}$ is the positive sequence current. At short-circuit without fault resistance, we have:

$$
Z_{\text {op }}=Z_{1}+Z_{2}=R_{1}+j X_{1}+R_{2}+j X_{2}=X_{1}(b+j c)=R+j X
$$

where

$$
b=b_{1}+b_{2} ; c=1+c_{2} ; R=b X_{1} ; X=c X_{1} .
$$

Sought for quantity $X_{1}$ is defined by (30).

When fault occurs through fault resistance $R_{\mathrm{f}}$, we have:

$$
\begin{gathered}
I_{1}=\frac{U}{Z_{1}+Z_{2}+R_{\mathrm{f}}} ; \\
\mathrm{Z}_{\mathrm{Opa}}=\frac{U}{I_{1}}=Z_{\text {op }}+R_{\mathrm{f}}=R_{\mathrm{a}}+j X_{\mathrm{a}}=b X_{1}+R_{\mathrm{f}}+j c X_{1} ; \\
R_{\mathrm{a}}=b X_{1}+R_{\mathrm{f}} ; X_{\mathrm{a}}=c X_{1} .
\end{gathered}
$$

Obviously

$$
X_{1}=\frac{X_{\mathrm{a}}}{c} ; \quad R_{\mathrm{f}}=R_{\mathrm{a}}-\frac{b}{c} X_{\mathrm{a}}
$$

For two-terminal line equations (35)...(40) hold when $R_{\mathrm{f}}$ stands for $R_{\mathrm{f}}^{*}$.

\section{Two Phase-to-ground Fault}

For metallic short circuit, the known formula for positive sequence fault current is [10]:

$$
I_{1}=\frac{U}{Z_{1}+\frac{Z_{2} Z_{0}}{Z_{2}+Z_{0}}},
$$


since operating impedance is:

$$
Z_{\text {op }}=\frac{U}{I_{1}}=Z_{1}+\frac{Z_{2} Z_{0}}{Z_{2}+Z_{0}}=R+j X,
$$

where $R$ and $X$ are given by numerical protection.

We shall consider a more complicated case when two shortcircuited phases close on the ground through fault resistance $R_{\mathrm{f}}$ (Fig. 8).

Then apparent operating impedance is:

$$
Z_{\text {opa }}=Z_{1}+\frac{Z_{2}\left(Z_{0}+R_{\mathrm{f}}\right)}{Z_{2}+\left(Z_{0}+R_{\mathrm{f}}\right)}=R_{\mathrm{a}}+X_{\mathrm{a}} .
$$

To facilitate calculations, such notations are introduced (Fig. 8b):

$$
Z_{0 \mathrm{f}}=Z_{0}+R_{\mathrm{f}} ; \Delta Z_{\mathrm{opa}}=\frac{Z_{2} Z_{0 \mathrm{f}}}{Z_{2}+Z_{0 \mathrm{f}}}
$$

Using abc-phase currents, all three current sequences $I_{0}, I_{1}$ and $I_{2}$ can be filtered. But we will need $I_{0}$ and $I_{1}$.

From Fig. 8b, c follows that

$$
\frac{I_{0}}{I_{1}}=\frac{Z_{2}}{Z_{2}+Z_{0 \mathrm{f}}} ; \frac{I_{0}}{I_{1}}=q
$$

Hence,

$$
Z_{0 \mathrm{f}}=\frac{1-q}{q} Z_{2} ; k=\frac{1-q}{q}=k^{\prime}+j k^{\prime \prime} ; Z_{0 \mathrm{f}}=k Z_{2} .
$$

From (49), using (51), through intermediate quantities (54) we arrive to the final formula (55):

$$
\begin{gathered}
Z_{0 \mathrm{f}}=R_{k 0}+j X_{k 0} ; R_{k 0}=k^{\prime} R_{2}-k^{\prime \prime} X_{2} \\
X_{k 0}=k^{\prime} X_{2}+k^{\prime \prime} R_{2} ; \Delta Z_{\mathrm{opa}}=\frac{R_{k 1}+j X_{k 1}}{R_{k}+j X_{k}} \\
R_{k 1}=R_{2} R_{k 0}-X_{2} X_{k 0} ; X_{k 1}=R_{2} X_{k 0}+X_{2} R_{k 0} \\
R_{k}=R_{2}+R_{k 0} ; X_{k}=X_{2}+X_{k 0} ; \Delta Z_{\mathrm{opa}}=\frac{R_{k 2}+j X_{k 2}}{D} \\
R_{k 2}=R_{k 1} R_{k}+X_{k 1} X_{k} ; X_{k 2}=X_{k 1} R_{k}-R_{k 1} X_{k} \\
D=R_{k}^{2}+X_{k}^{2} \cdot \\
Z_{\text {opa }}=R_{\mathrm{a}}+j X_{\mathrm{a}}=\frac{U}{I_{1}}=R_{1}+j X_{1}+\frac{R_{k 2}+j X_{k 2}}{D}
\end{gathered}
$$

Isolating in (55) imaginary component and expressing $R_{k 2}$, $X_{k 2}$ and $D$ by (22) and (23), we have:

$$
X_{\mathrm{a}}=X_{1}+\frac{X_{1} x_{k 2}}{d} ; X_{1}=\frac{X_{\mathrm{a}}}{1+x_{k 2} / d},
$$

where

$$
\begin{aligned}
& d=r_{k 2}+x_{k 2} ; \quad r_{k 2}=r_{k 1} r_{k}+x_{k 1} x_{k} ; x_{k 2}=x_{k 1} r_{k}-r_{k 1} x_{k} ; \\
& r_{k 1}=b_{2} r_{k 0}-c_{2} x_{k 0} ; x_{k 1}=b_{2} x_{k 0}+c_{2} r_{k 0} ; r_{k}=b_{2}+r_{k 0} ; \\
& x_{k}=c_{2}+x_{k 0} ; r_{k 0}=k^{\prime} b_{2}-k^{\prime \prime} c_{2} ; x_{k 0}=k^{\prime} c_{2}+k^{\prime \prime} b_{2} .
\end{aligned}
$$

To define the fault resistance $R_{\mathrm{f}}$, we use the first expression of batch (54):

$$
\begin{aligned}
& R_{\mathrm{Of}}=\operatorname{Re}\left(Z_{0 \mathrm{f}}\right)=R_{k 0}=X_{1}\left(k^{\prime} b_{2}-k^{\prime \prime} c_{2}\right), \\
& R_{\mathrm{f}}=R_{\mathrm{Of}}-R_{0}=X_{1}\left(k^{\prime} b_{2}-k^{\prime \prime} c_{2}-b_{0}\right) .
\end{aligned}
$$

Numerical check confirms the derived expressions.

The two-terminal line requires iterative calculations of $X_{1}$. The fault is fed from two sides (Fig. 9a). To define the distance to fault place (it is the same as to define the unknown $X_{1}$ ), the measured data of $U$ and $I$ are insufficient. It is to be known extra one quantity from the right side of the fault. Here it is meant that this quantity is emf $E_{\mathrm{s}}$. Summary impedances $Z_{\Sigma}$ are known initially. So, to the right of the fault place, we have impedances $Z_{\mathrm{r}}$ :

$$
Z_{\mathrm{r}}=Z_{\Sigma}-Z
$$

where $Z$ is sought for impedance from the monitoring point to fault place.

To calculate any impedance $Z_{\mathrm{r}}$, it is necessary to assume some impedance $X_{1 \text { as }}$ and then, observing (22) and (23), to determine all the necessary impedances $Z_{\mathrm{r}}$ basing on reactance $X_{1 \text { as }}$, which is the product of specific reactance $x_{1}$ and assumed as distance to fault place $l_{\text {as. }}$.

In accordance with Fig. 9b, c:

$$
Z_{2 \mathrm{e}}=\frac{Z_{2} Z_{2 \mathrm{r}}}{Z_{2}+Z_{2 \mathrm{r}}} ; Z_{0 \mathrm{e}}=\frac{Z_{0} Z_{0 \mathrm{r}}}{Z_{0}+Z_{0 \mathrm{r}}} ; Z_{0 \mathrm{fe}}=R_{\mathrm{f}}+Z_{0 \mathrm{e}} .
$$

Summary direct sequence current is:

$$
I_{1 \Sigma}=I_{1}+I_{1 \mathrm{r}}=I_{1} \kappa
$$

where $\kappa$ is a presumed, as yet unknown, factor. To define the current $I_{1 \mathrm{r}}$, we must know $Z_{3}$ [12] which is the result of $Z_{2 \mathrm{e}}$ and

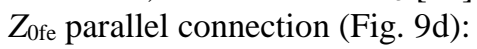

$$
Z_{3}=\frac{Z_{2 \mathrm{e}} Z_{0 \mathrm{fe}}}{Z_{2 \mathrm{e}}+Z_{0 \mathrm{fe}}}
$$

But we cannot determine $Z_{3}$ since we do not know $Z_{0 \text { fe }}$, because the fault resistance $R_{\mathrm{f}}$ is the second, besides $X_{1}$, unknown. It is unproductive to assume two quantities $X_{1}$ and $R_{\mathrm{f}}$.

Similarly as for one-terminal line (see (52)), we presume

$$
\ddot{q}=\frac{I_{0 \Sigma}}{I_{1 \Sigma}}=\frac{Z_{2 \mathrm{e}}}{Z_{2 \mathrm{e}}+Z_{0 \mathrm{fe}}} .
$$


Based on Fig. 9b and expressions (52) and (64), we have:

$$
\ddot{q}=\frac{I_{0} Z_{0 \Sigma} / Z_{0 \mathrm{r}}}{\kappa I_{1}}=\frac{q Z_{0 \Sigma}}{\kappa Z_{0 \mathrm{r}}} ; Z_{0 \Sigma}=Z_{0}+Z_{0 \mathrm{r}} .
$$

Through the string of formulas:

$$
\begin{array}{r}
Z_{0 \mathrm{fe}}=Z_{2 \mathrm{e}} \frac{1-\ddot{q}}{\ddot{q}}=Z_{2 \mathrm{e}} \ddot{k} ; \ddot{k}=\frac{1-\ddot{q}}{\ddot{q}} ; \\
Z_{3}=\frac{Z_{2 \mathrm{e}} \ddot{k}}{1+\ddot{k}}=Z_{2 \mathrm{e}}(1-\ddot{q})=Z_{2 \mathrm{e}} \frac{\kappa Z_{0 \mathrm{r}}-q Z_{0 \Sigma}}{\kappa Z_{0 \mathrm{r}}} .
\end{array}
$$

Using loop current method [12] we find $I_{l \mathrm{r}} / I_{l}$ :

$$
\ddot{\chi}=\frac{I_{1 \mathrm{r}}}{I_{1}}=\frac{E_{\mathrm{s}} Z_{1}+\left(E_{\mathrm{s}}-U\right) Z_{3}}{U Z_{1 \mathrm{r}}-\left(E_{\mathrm{s}}-U\right) Z_{3}} .
$$

Quantity $\kappa$ defined by (63) can be redefined:
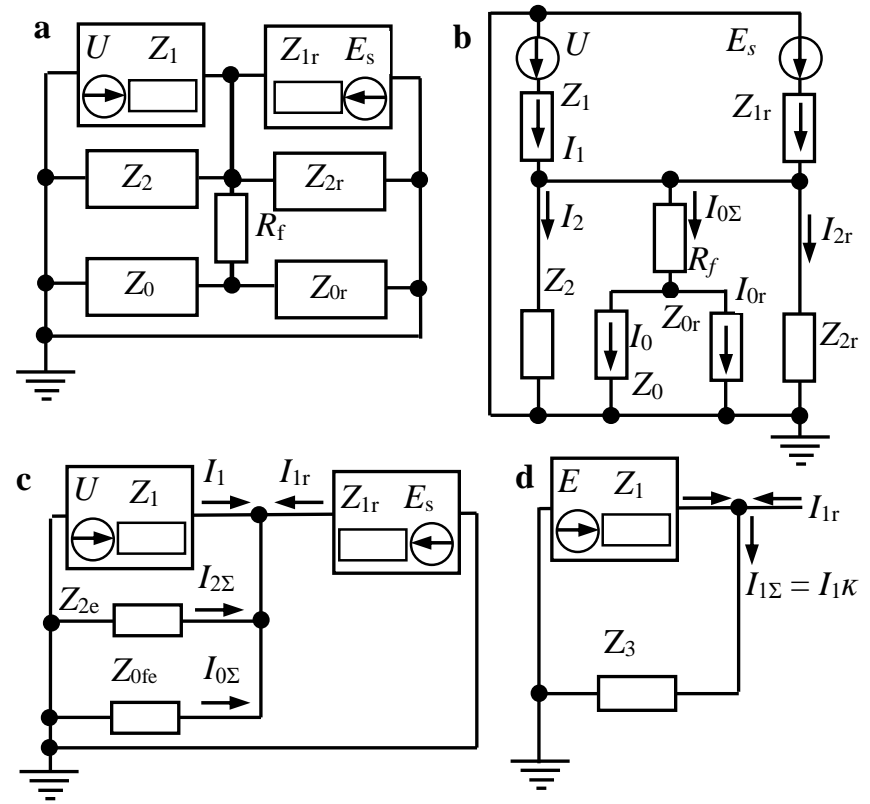

Fig. 9. Two-phase-to-ground fault in a two-terminal line:

$\mathrm{a}, \mathrm{b}, \mathrm{c}, \mathrm{d}-$ consecutive circuit diagrams in line with mathematical considerations.

$$
\kappa=\frac{I_{1}+I_{1 \mathrm{r}}}{I_{1}}=1+\ddot{\chi}
$$

where from

$$
\kappa=\frac{Z_{0 \mathrm{r}}\left(U Z_{1 r}+E_{\mathrm{s}} Z_{1}\right)-\left(E_{s}-U\right) Z_{2 \mathrm{e}} q Z_{0 \Sigma}}{Z_{0 \mathrm{r}}\left[U\left(Z_{1 \mathrm{r}}+Z_{2 \mathrm{e}}\right)-E_{\mathrm{s}} Z_{2 \mathrm{e}}\right]} .
$$
is:

Apparent impedance given by protection observing Fig. 9d

$$
\ddot{Z}_{\mathrm{a}}=\ddot{R}_{\mathrm{a}}+j \ddot{X}_{\mathrm{a}}=U / I_{1}=Z_{1}+\Delta \ddot{Z}
$$

So far as through $Z_{3}$ current $I_{1}+I_{1 \mathrm{r}}$ flows, the source of the current $I_{1}$ feels besides impedance $Z_{1}$, yet the impedance $\Delta \ddot{Z}$ which is $\kappa$ times grater than $\mathrm{Z}_{3}$ :

$$
\Delta \ddot{Z}=\kappa Z_{3}
$$

For assumed $X_{\text {las }}$ (for assumed distance $l_{\mathrm{as}}$ ), the result of the first iteration is obtained. Isolating imaginary and real components of (70) we have:

$$
\begin{gathered}
X_{1}{ }^{(1)}=X_{\mathrm{a}}-\operatorname{Im}\left(\Delta \ddot{Z}^{(1)}\right) ; R_{\mathrm{f}}{ }^{(1)}=Z_{0 \mathrm{fe}}{ }^{(1)}-Z_{0 \mathrm{e}}{ }^{(1)}, \\
Z_{0 \mathrm{fe}}{ }^{(1)}=Z_{2 \mathrm{e}}{ }^{(1)} \ddot{k}^{(1)} .
\end{gathered}
$$

At that iterations converge faster when

$$
X_{\mathrm{as}}^{(n+2)}=\left(X_{\mathrm{as}}^{(n)}+X_{\mathrm{as}}^{(n+1)}\right) / 2 \text {. }
$$

With more iterations, $R_{\mathrm{f}}$ converges to real value (see (61).

For reverse fault, $X_{1}{ }^{(1)}$ is negative for a positive value of $X_{\text {las. }}$. The numerical example: $U=10 \mathrm{~V} ; E_{s}=12 \mathrm{~V} ; l_{\mathrm{lin}}=20 \mathrm{~km}$; $x_{1}=0.4 \Omega / \mathrm{km} ; \quad b_{1}=b_{2}=0.25 ; \quad c_{2}=1 ; \quad b_{0}=0.375 ; \quad c_{0}=3$; $Z_{1 \mathrm{~s}}=0.5+3 i ; Z_{2 \mathrm{~s}}=0.5+4 i ; Z_{0 \mathrm{~s}}=0.75+4 i$. Two-phase to earth fault with $R_{\mathrm{f}}=5 \Omega$ occurs at $10 \mathrm{~km}$ from protection. At $l_{\mathrm{as}}{ }^{(1)}=15 \mathrm{~km} \quad l^{(1)}=3.8615 \mathrm{~km}, R_{\mathrm{f}}^{(1)}=5.6255+j 0.7489 \Omega$; at $l_{\mathrm{as}}{ }^{(2)}=(15+3.8615) / 2=9.43077 \quad \mathrm{~km} \quad l^{(2)}=10.6175 \mathrm{~km}$, $R_{\mathrm{f}}^{(2)}=4.8328+j 0.0789 \Omega ; \quad \ldots \quad l_{\mathrm{as}}{ }^{(4)}=9.9988 \mathrm{~km}$, $l^{(4)}=10.0013 \mathrm{~km}, R_{\mathrm{f}}^{(4)}=4.9997+j 0.00016 \Omega$.

\section{CONCLUSION}

1. Balancing the power line with an unbalanced load requires large load disbalance. It would be beneficial to investigate the possibility of balancing the power line by way of artificially increasing the mutual impedance between outer phases of flat arrangement.

2. For flat arrangement, the indices of zero sequence current are best when OGW is over the middle phase and slightly smaller than for the line without OGW. Negative sequence current changes little.

3. Two parallel balanced but not transposed lines and doublecircuit lines without OGW have external mutual Fortesque impedances between all sequences.

5. Some mutual impedances of the line with OGW strongly differ from those without OGW.

6. The impact of mutual impedances between parallel lines can be eliminated by additive measures.

7. Fault analysis of untransposed lines can be reduced to that of transposed ones provided that $Z_{1} \neq Z_{2}$ is accepted.

8. Fault calculations can be made easier when complex Fortesque impedances are described through positive sequence reactance to fault place.

9. To define fault location in a two-terminal line, measured data only from monitored side are insufficient. Some trustworthy assumption or extra value is necessary.

10. The most complicated case of distance determination is for two phase-to-ground fault through fault resistance in a twoterminal line. 


\section{ACKNOWLEDGMENT}

I express my gratitude to Dr. sc. ing. S. Rubcov for providing information on the parameters of transmission lines.

\section{REFERENCES}

[1] Y. Hase, Handbook of Power System Engineering. Chichester, West Sussex, England: John Wiley \& Sons Ltd, 2008, pp. 1-44.

[2] Fernando Calero, "Mutual Impedance in Parallel Lines - Protective Relaying and Fault Location Considerations," [Online]. Available: www.selinc.com/WorkArea/DownloadAsset.aspx id=3488

[3] P. Giridhar Kini, R. C. Bansal and R. S. Aithal, "Impact of voltage unbalance on the performance of three-phase induction motor," The South Pacific Journal of Natural Science, vol. 24, no. 1, pp. 45-50. http://dx.doi.org/10.1071/SP06007

[4] Electric Power Research Institute, "Voltage Unbalance: Power Quality Issues, Related Standards and Mitigation Techniques: Effect of Unbalanced Voltage on End Use Equipment Performance," [Online]. Available: www.epri.com/abstracts/pages/

[5] E. Muljadi, et al., "Understanding the Unbalanced-Voltage Problem in Wind Turbine Generation," in IEEE Industry Applications Conf., Phoenix, AZ, Oct. 3 - Oct. 7, 1999. http://dx.doi.org/10.1109/IAS.1999.801678

[6] A. Vanags, "Elektriskie tīkli un sistēmas," Riga: RTU, 2005, p. 125

[7] A. M. Gashimov, A. R. Babayeva and A. Nayir, "Transmission line transposition," [Online]. Available: www.emo.org.tr/ekler/97a39505016683c.ek.pdf

[8] J. Survilo, "Impact of untransposed power lines," Scientific Journal of Riga Technical University, Power and Electrical Engineering, vol. 32, pp. 29-34, Dec. 2014.

[9] The Electrical Engineering Site, "Ideal Transformer and Characteristics of Ideal Transformer," [Online]. Available: www.electrical4us.com/idealtransformer-characteristics-of-ideal-transformer/

[10] A. Ulyanov, Elektromagnitniye perehodniye processy v elektricheskih sistemah, Moskva: Energiya, 1970, pp. 316-322. (in Russian)

[11] K. Zimmerman and D. Castello, "Impedance based fault location experience," in 58th Annu. Conf. for Protective Relay Engineers, 2005. http://dx.doi.org/10.1109/CPRE.2005.1430435

[12] L. Neyman and K. Demirchian, Teoreticheskiye osnovy elektrotehniki. Tom perviy, Leningrad: "Energiya," 1967, p. 205. (in Russian) 